\title{
Hard X-ray Wiggler Front End Filter Design
}

\author{
Horst Schulte-Schrepping and Ulrich Hahn
}

Deutsches Elektronen-Synchrotron DESY, Notkestrasse 85, 22603 Hamburg, Germany

\begin{abstract}
The front end filter design and implementation for the new HARWI-II hard X-ray wiggler at DORIS-III at HASYLAB/DESY is presented. The device emits a total power of $30 \mathrm{~kW}$ at $150 \mathrm{~mA}$ storage ring current. The beam has a horizontal width of $3.8 \mathrm{mrad}$ and a central power density of $54 \mathrm{~W} / \mathrm{mm}^{2}$ at $26 \mathrm{~m}$ distance to the source. The filter section located in the ring tunnel has been introduced to tailor the thermal loads at the downstream optical components. The high power density and the high total power at the filter section are handled with a layered design. Glassy carbon filters convert the absorbed power into thermal radiation to lower the heat load to an acceptable level for water cooled copper filters. The requirements in beam size and filtering are addressed by separating the filter functions in three units which are switched individually into the beam.
\end{abstract}

Keywords: Synchrotron radiation, wiggler, beamline, filter

PACS: 07.85.Qe, 42.79.Ci, 41.50.+h

\section{INTRODUCTION}

The design of the new HARWI front-end enables the GKSS material science centre [1] to provide a tailored photon beam at the monochromators and the experimental stations. The wiggler insertion device emits a total power of $30 \mathrm{~kW}$ at $150 \mathrm{~mA}$ storage ring current. The beam has a horizontal width of $3.8 \mathrm{mrad}$ and a central power density of $54 \mathrm{~W} / \mathrm{mm}^{2}$ at $26 \mathrm{~m}$. In Fig.1 the flux density of the wiggler [2] is plotted for the current DORIS-III operation parameters.

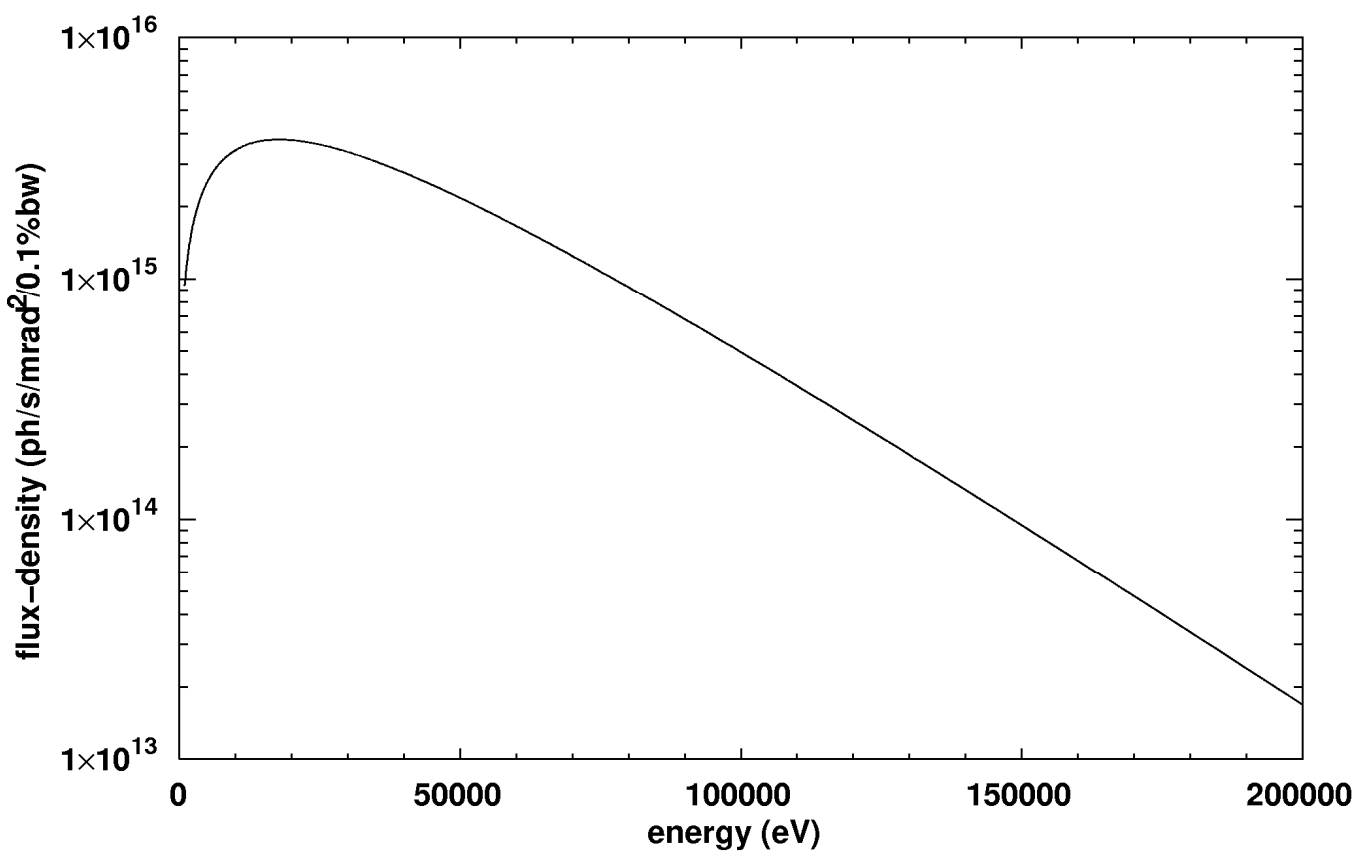

FIGURE 1. Flux density plot of the new HARWI wiggler at DORIS-III with a critical energy of 26.8keV. A total power of $30 \mathrm{~kW}$ at $150 \mathrm{~mA}$ storage ring current is radiated at minimum wiggler gap.

CP879, Synchrotron Radiation Instrumentation: Ninth International Conference, edited by Jae-Young Choi and Seungyu Rah

(C) 2007 American Institute of Physics 978-0-7354-0373-4/07/\$23.00 


\section{FILTER SECTION DESIGN}

The front-end vacuum system has been rebuilt to accept this powerful wide wiggler beam. A photon beam filtering section in the ring tunnel was introduced to handle the high thermal loads in front of the optical components. The section was adapted to the requirements of the experiments. The high power density together with a high total power at the filter section can only be handled with a layered design. The ability of carbon filters to convert the absorbed power to thermal radiation is used to lower the heat load to an acceptable level for water cooled copper filters. The different requirements in beam size and filtering are addressed by separating the filter functions in three units grouped in two filter units. They can be switched individually into the beam as shown in Fig. 2 in a side view and in Fig.3 for each filter separately from the front.

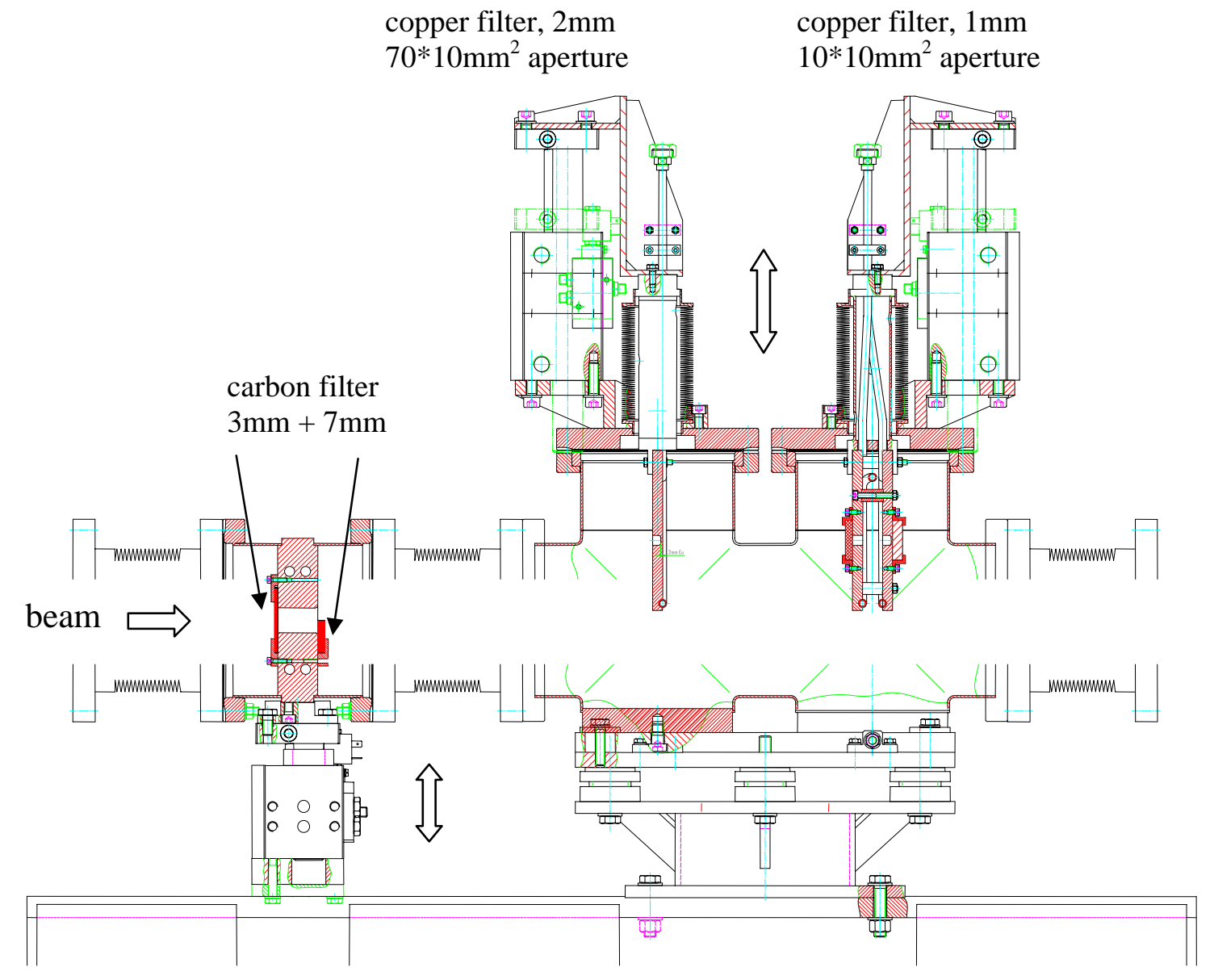

FIGURE 2. Schematic view of the filter unit assembly installed in the HARWI front-end. The separation into three separate units allows a flexible combination of attenuations and fulfils the requirements in beam size and filtering of the downstream optics and experiments. The white wiggler beam enters from the left and is permanently filtered by a 3mm thick carbon filter; another $7 \mathrm{~mm}$ of carbon are added by moving the whole assembly upwards. The copper filters with a thickness of $2 \mathrm{~mm}$ and $1 \mathrm{~mm}$ are attached to linear feed-throughs and are moved down into the beam path by pneumatic actuators outside the vacuum. All filters are water cooled. 


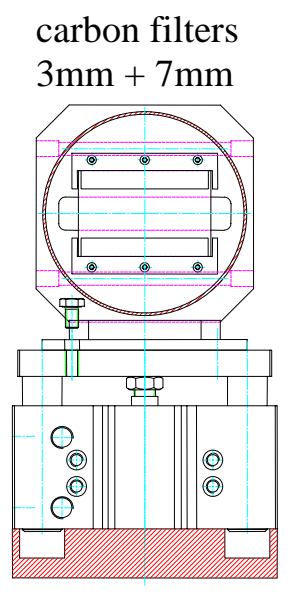

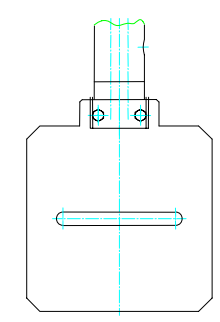

copper filter, $2 \mathrm{~mm}$ $70 * 10 \mathrm{~mm}^{2}$ aperture machined into a copper block

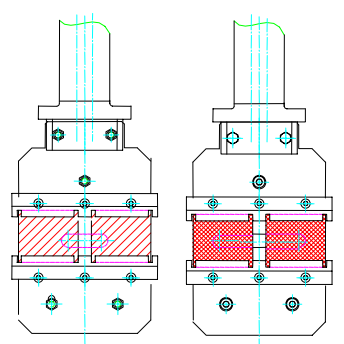

copper filter, $1 \mathrm{~mm}$ $10 * 10 \mathrm{~mm}^{2}$ aperture

left: carbon absorber (view with the beam)

right: tungsten absorber (view against the beam)

FIGURE 3. The three filter units seen in beam direction. Left: the filter unit with $3 \mathrm{~mm}$ and $7 \mathrm{~mm}$ thick carbon plates mounted on a copper block in a separate vacuum vessel. The whole assembly is decoupled from the beam pipe by bellows (see Fig. 2). The upwards movement changes from the permanent $3 \mathrm{~mm}$ to the $10 \mathrm{~mm}(3 \mathrm{~mm}+7 \mathrm{~mm})$ filter position. Centre: The $2 \mathrm{~mm}$ thick copper filter with an aperture of $70 * 10 \mathrm{~mm}^{2}$ is machined into a $10 \mathrm{~mm}$ thick water cooled copper plate. Right: both sides of the $1 \mathrm{~mm}$ thick copper filter with an aperture of $10 * 10 \mathrm{~mm}^{2}$. The carbon absorbers are used in combination with the $10 \mathrm{~mm}$ setting of the first carbon filter system to manage the total absorbed power in the thick part of the copper plate. The horizontal beam size after passing the $1 \mathrm{~mm}$ thin filter window is defined by tungsten plates.

\section{THERMAL DESIGN}

The $3 \mathrm{~mm}$ thick carbon filter will be permanently in the white wiggler beam and provides a basic attenuation of the beam. It acts as a high pass filter. This filter provides the thermal protection for all additional filter sections and the beryllium window which terminates the beamline vacuum. An optional additional carbon filter with a thickness of $7 \mathrm{~mm}$ reduces the heat load on the following copper filters and the first crystal in the monochromator section. For the hard X-ray options of beamline operation additionally either a $1 \mathrm{~mm}$ thick and $10 \mathrm{~mm}$ wide or a $2 \mathrm{~mm}$ thick and 70mm wide copper filter can be inserted into the beam path. Both copper filters withstand the thermal load with $10 \mathrm{~mm}$ carbon in front. In Table 1, the power management of the filter section is summarized.

TABLE 1. Filter unit power management

\begin{tabular}{|l|c|c|c|c|c|}
\hline $\begin{array}{l}\text { Aperture size at a } \\
\text { position of 26m from } \\
\text { the source }\end{array}$ & $\begin{array}{c}\text { Total power in the } \\
\text { white beam inside } \\
\text { the aperture }\end{array}$ & $\begin{array}{c}\text { Total power after } \\
\text { 3mm carbon }\end{array}$ & $\begin{array}{c}\text { Total power } \\
\text { after 10mm } \\
\text { carbon }\end{array}$ & $\begin{array}{l}\text { Total power } \\
\text { after 10mm } \\
\text { carbon and } \\
\text { 1mm copper }\end{array}$ & $\begin{array}{c}\text { Total power } \\
\text { after 10mm } \\
\text { carbon and } \\
\text { 2mm copper }\end{array}$ \\
\hline $10 * 10 \mathrm{~mm}^{2}$ & $2980 \mathrm{~W}$ & $1960 \mathrm{~W}$ & $1260 \mathrm{~W}$ & $100 \mathrm{~W}$ & \\
\hline $70 * 10 \mathrm{~mm}^{2}$ & $19600 \mathrm{~W}$ & $12600 \mathrm{~W}$ & $8000 \mathrm{~W}$ & & $700 \mathrm{~W}$ \\
\hline
\end{tabular}

The primary slit in front of the filter section cuts the horizontal opening angle down from 3.8mrad to a maximum horizontal opening angle of $2.7 \mathrm{mrad}$. At a distance of $26 \mathrm{~m}$ from the source, the relevant total powers for the filter design with $10 * 10 \mathrm{~mm}^{2}$ and $70 * 10 \mathrm{~mm}^{2}$ apertures are $2980 \mathrm{~W}$, and $19600 \mathrm{~W}$, respectively. 


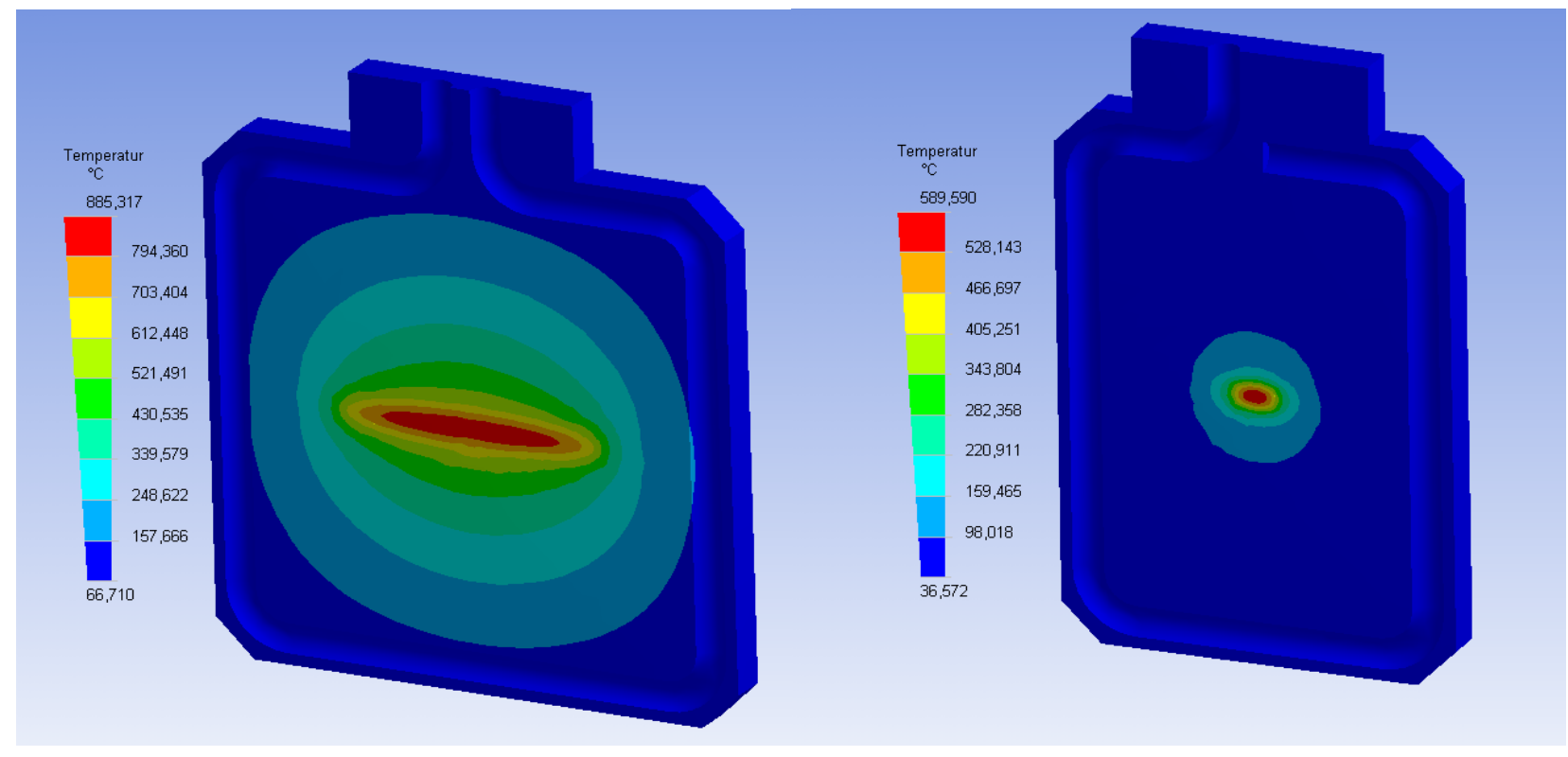

FIGURE 4. Finite element calculations (FEM) of the copper filters for the highest possible heat load (DORIS with $150 \mathrm{~mA}$ and closed wiggler gap) on the filter. For the calculations a uniform radiation power distribution over a strip height of $5 \mathrm{~mm}$ is assumed. The filter on the left $\left(70 * 10 \mathrm{~mm}^{2}\right.$ and $2 \mathrm{~mm}$ thick) shows a temperature distribution close to critical values. The other filter $\left(10 * 10 \mathrm{~mm}^{2}\right.$ and $1 \mathrm{~mm}$ thick) will heat up to a temperature of $600^{\circ} \mathrm{C}$ in the centre.

The layout of the individual filters is based on FEM calculations with ANSYS 8.0 design space. The incident wiggler power distribution has been calculated with the SPECTRA [3] code. The design values assumed a density of $2.25 \mathrm{~g} / \mathrm{cm}^{3}$ for the carbon filters. In the actual technical realization glassy carbon filters with a density of $1.6 \mathrm{~g} / \mathrm{cm}^{3}$ and with a correspondingly larger thickness have been installed.

The calculation shows that the peak temperatures of the $\mathrm{Cu}$ filters reach critical values for the highest possible heat load. For the operation with closed wiggler gap, the beam height has to be reduced to 3mm with the primary slit system in front of the filter unit. This will lead to an acceptable power level for the filter units. The beamline equipment protection system takes care that the switching of the filters is possible only when the wiggler gap is open or the photon shutter in front of the filters is closed. The filter units have been installed at the end of 2005 . First operational experiences with reduced total power show the usefulness of the filter unit for the protection of the optical components and experimental setups.

\section{REFERENCES}

1. F. Beckmann, et al., "HARWI-II, The New High-Energy Beamline for Materials Science at HASYLAB/DESY", AIP Conference Proceedings SRI-2003, (2004) 705, 392-395.

2. M. Tischer, L. Gumprecht, J. Pflüger, T. Vielitz, “A New Hard X-ray Wiggler for DORIS-III”, these proceedings.

3. T. Tanaka and H. Kitamura, J. Synchrotron Radiation 8, 1221-1228 (2001). 